\title{
Transatlantica
}

Revue d'études américaines. American Studies Journal

Rebecca Solnit. River of Shadows : Eadweard Muybridge and the Technological Wild West. New York : Viking Penguin, 2003. 305 p., index, ill.

\section{François Brunet}

\section{(2) OpenEdition}

\section{Journals}

Édition électronique

URL : http://journals.openedition.org/transatlantica/848

DOI : $10.4000 /$ transatlantica.848

ISSN : 1765-2766

Éditeur

AFEA

Référence électronique

François Brunet, «Rebecca Solnit. River of Shadows : Eadweard Muybridge and the Technological Wild West. », Transatlantica [En ligne], 1 | 2005, mis en ligne le 22 avril 2006, consulté le 29 avril 2021. URL http://journals.openedition.org/transatlantica/848 ; DOI : https://doi.org/10.4000/transatlantica.848

Ce document a été généré automatiquement le 29 avril 2021.

\section{c) (i) $\Theta$}

Transatlantica - Revue d'études américaines est mis à disposition selon les termes de la licence Creative Commons Attribution - Pas d'Utilisation Commerciale - Pas de Modification 4.0 International. 


\section{Rebecca Solnit. River of Shadows : Eadweard Muybridge and the Technological Wild West.}

New York : Viking Penguin, 2003. 305 p., index, ill.

\section{François Brunet}

1 «Le monde tel que nous le connaissons aujourd'hui a commencé en Californie dans le dernier quart du dix-neuvième siècle, et un homme du nom d'Eadweard Muybridge y fut pour beaucoup » : ainsi s'ouvre le prière d'insérer de ce nouveau livre de Rebecca Solnit, auteur déjà célèbre de plusieurs ouvrages sur la Californie et l'Ouest ainsi que d'une histoire de la marche (Wanderlust). Muybridge, c'est, bien sûr, le père (américain) du cinéma et l'analyste de la locomotion humaine et animale, accessoirement l'un des plus grands photographes de l'Ouest américain au 19e siècle; mais tandis que pour chacun de ces rôles il a été souvent surclassé dans l'historiographie (par Etienne-Jules Marey et les frères Lumière pour la généalogie du cinéma, du moins en France, par Carleton E. Watkins pour la photographie paysagiste), sa carrière passablement erratique et émaillée par divers incidents sordides, dont le meurtre de l'amant de sa jeune épouse, n'avait jamais, jusqu'ici, reçu un éclairage aussi puissant. Ce livre n'est pas, toutefois, une biographie, ou alors c'est une « éco-biographi », version grand public d'un modèle « écocritique » qui, mélangeant écologie, régionalisme et cultural studies, connaît un succès croissant aux Etats-Unis, dans l'Ouest surtout.

2 La thèse de Solnit est assez simple: de ses études géologiques à ses expériences chronophotographiques sur le cheval Occident de Leland Stanford, magnat du chemin de fer, gouverneur de l'Etat et fondateur de l'université qui porte son nom, et de ses expériences à la mise en œuvre du zoopraxiscope et à la renommée internationale, Muybridge a été au centre de l'ascension technologique, économique et culturelle de la Californie à la fin du 19e siècle. La force de cette thèse est d'assigner un contenu symbolique simple (quoique pas très original en lui-même) à l'ascension de la Californie : la conquête du mouvement, de "l'annihilation du temps et de l'espace » par le chemin de fer et de l'organisation par celui-ci de la temporalité moderne au 
cinématographe, en passant par l'analyse de la locomotion. C'est le mouvement, son accélération, son analyse et sa valorisation, qui servent de levier à cette ascension d'une région qui, pour la première fois dans l'histoire des Etats-Unis, retourne le sens de l'expansion vers l'est et produit ainsi le premier contrepoids régional important à l'influence de l'espace atlantique.

3 Aussi le désappointement du peintre animalier Meissonnier à la vue des figures du trot chevalin réalisées par Muybridge prend-il ici la valeur d'un bouleversement géostratégique. Muybridge, Anglais de naissance qui retournera finir ses jours sur la Tamise après avoir, semble-t-il, aimé l'espace de l'Ouest, a joué dans cette contreexpansion un rôle d'instrument, de catalyseur, et, sinon de commentateur (il écrivit fort peu), du moins d'illustrateur, particulièrement doué. Et il faut savoir gré à Solnit de situer à sa juste place l'œuvre du photographe le plus inventif de Yosemite, du technicien hors pair de la plaque de verre et de l'auteur d'un prodigieux panorama de San Francisco en 1877, sans parler de son rôle éminent dans la genèse de la chronophotographie et du cinéma, rôle que continue d'occulter en France l'inextinguible gloire posthume de Marey. L'homme Muybridge ne sort sans doute pas grandi de cette relecture, car Solnit confirme son tempérament fantasque, voire dérangé, et surtout morne (séquelle, peut-être, d'un grave accident de diligence en 1855); mais sa carrière, jusqu'ici souvent résumée par l'appât du gain, devient plus homogène et plus intelligible en servant de pivot à un récit alerte, captivant sinon toujours convaincant, de l'essor de la Californie. Quant à ce récit, en dépit de ses récriminations à la Paul Virilio sur la disparition du temps ancestral et l'accélération technologique comme source du monde global et de ses maux, il risque de passer, en France, comme l'avatar régionaliste de la vieille antienne du modernisme américain. Il n'est pas interdit, cependant, d'y voir une bonne introduction à l'histoire culturelle de l'ère post-moderne.

\section{INDEX}

Thèmes : Recensions

\section{AUTEUR}

\section{FRANÇOIS BRUNET}

Université Paris 7 - Denis Diderot 